\title{
O COMÉRCIO ELETRÔNICO
}

\section{EVOLUI E CONSOLIDA-SE NO}

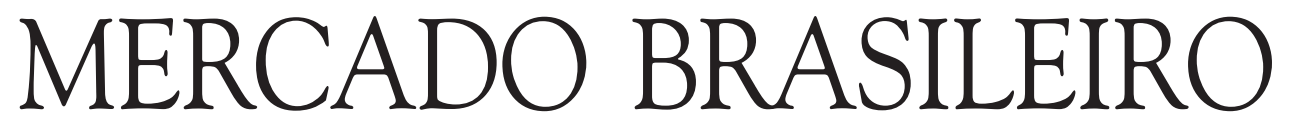

\author{
Alberto Luiz Albertin \\ Professor do Departamento de Informática e de Métodos Quantitativos Aplicados à Adminis- \\ tração da EAESP/FGV, Coordenador do Centro de Informática Aplicada (CIA) da EAESP/FGV \\ e do Programa de Excelência em Negócios na Era Digital do CIA da EAESP/FGV. \\ E-mail: albertin@fgvsp.br
}

\begin{abstract}
RESUMO
As organizações brasileiras têm utilizado largamente as tecnologias de informação e comunicação para interligar suas várias áreas, fornecedores e clientes, processar um número muito grande de transações e atender a uma quantidade de clientes de forma rápida, segura e, muitas vezes, personalizada. 0 ambiente empresarial, tanto em nível mundial quanto em nacional, tem passado por inúmeras mudanças nos últimos anos, as quais têm sido consideradas diretamente relacionadas com as tecnologias de informação. Um dos aspectos mais importantes desse novo contexto é o surgimento do ambiente digital, que

passou a permitir, de fato, a realização de negócios na era digital e do comércio eletrônico.
\end{abstract}

Este artigo analisa esse novo ambiente e conclui que o comércio eletrônico no mercado brasileiro está consolidado e apresenta claros sinais de evolução, mesmo que ainda possa ser considerado em um estágio intermediário de expansão. A análise dessa evolução, com as realizações já empreendidas, possibilita a identificação da busca pelo novo ambiente de negócio, formado por comunidades de pessoas e empresas.

\section{ABSTRACT}

Brazilian organizations have widely been using the information and communication technologies to link their several areas, vendors and clients, to process a very large number of transactions and to attend to a quantity of clients on a fast, certain and, many times, personalized form. The enterprise environment, in the world level as well as in the national level, has passed through countless changes in the last years, which have been considered directly related to the information technologies. One of the most important aspects of this new context is the appearance of the digital environment, that made possible, in fact, the digital age business and the electronic commerce. This article analyzes this new environment and concludes that the electronic commerce in the Brazilian market is consolidated and shows clear signals of evolution, even though it can still be considered in an intermediary level of expansion. The analysis of this evolution, with already undertaken achievements, enables the identification of the search for the new business environment, made by communities of people and companies.

\section{PALAVRAS-CHAVE}

Comércio eletrônico, negócios na era digital, negócios eletrônicos, mercado brasileiro, tecnologia de informação.

KEY WORDS

Electronic commerce, business in the digital age, electronic business, Brazilian market, information technology. 


\section{INTRODUÇÃO}

As organizações brasileiras têm utilizado amplamente as tecnologias de informação e comunicação para interligar suas várias áreas, fornecedores e clientes, processar um número muito grande de transações e atender a uma quantidade de clientes de forma rápida, segura e, muitas vezes, personalizada, conforme argumentado por Albertin (1999).

O ambiente empresarial, tanto em nível mundial quanto em nacional, tem passado por inúmeras mudanças nos últimos anos, as quais têm sido consideradas diretamente relacionadas com as tecnologias de informação (TI). Um dos aspectos mais importantes desse novo contexto é o surgimento do ambiente digital, que passou a permitir, de fato, a realização de negócios na era digital e do comércio eletrônico.

O comércio eletrônico (CE) já é uma realidade em diversos setores da economia, estando em um estágio de evolução intermediário. O cenário atual, mesmo que não uniforme para todas as empresas em um índice ainda não muito elevado, permite avaliar tal evolução e identificar suas tendências.

Essa evolução apresenta diversas conseqüências a serem entendidas para o aproveitamento efetivo das potencialidades desse ambiente e para o tratamento adequado dos riscos envolvidos em uma situação com tal poder revolucionário. As principais áreas de conseqüências podem ser resumidas na mudança de relevância dos aspectos a serem considerados pelas empresas para a utilização do CE e na importância atribuída para as contribuições desse novo ambiente de negócios na era digital.

Este artigo analisa o estágio de evolução do CE no Brasil utilizando as principais conclusões da "Pesquisa FGV de Comércio Eletrônico no Mercado Brasileiro”, edição 2000 (Albertin, 2000d), e do projeto de pesquisa de Albertin (2000b) "Comércio eletrônico: situação atual e tendências", realizado entre julho de 1999 e março de 2000, com o apoio do Núcleo de Pesquisas e Publicações (NPP) da Escola de Administração de Empresas de São Paulo (EAESP) da Fundação Getulio Vargas (FGV).

\section{NEGÓCIOS NA ERA DIGITAL}

O novo ambiente empresarial é fundamentalmente baseado no ambiente digital, que tem como componente básico a Internet, considerada infra-estrutura de comunicação pública de acesso fácil, livre e de baixo custo.

A Internet e seus serviços básicos, tais como correio eletrônico e a World Wide Web, têm criado um novo espaço para a realização de negócios. Esse novo ambiente tem fornecido para os agentes econômicos, tanto empresas quanto indivíduos, canais alternativos para trocar informações, comunicar-se, transferir diferentes tipos de produtos e serviços e iniciar transações comerciais.

A exploração do ambiente digital, composta pela utilização ampla e intensa das tecnologias de informação e comunicação que formam a infra-estrutura de comunicação pública e que inclui a Internet, está em um estágio intermediário. A evolução prevê a sua utilização para o fornecimento e a troca de informação, a comunicação e a realização de transações, tendo sido iniciada com a publicação de informações institucionais e devendo desenvolver-se até a criação de comunidades, tanto de empresas quanto de pessoas, formando o ambiente de negócios na era digital.

\section{COMÉRCIO ELETRÔNICO}

Albertin (2000a) definiu que comércio eletrônico é a realização de toda a cadeia de valores dos processos de negócio em um ambiente eletrônico, por meio da aplicação intensa das tecnologias de comunicação e de informação, atendendo aos objetivos de negócio. Os processos podem ser realizados de forma completa ou parcial, incluindo as transações negócio-a-negócio, negócio-a-consumidor e intra-organizacional, em uma infra-estrutura de informação e comunicação predominantemente pública, de acesso fácil, livre e de baixo custo.

Essa definição permite entender que a realização dessa cadeia de valores deve incluir desde a distribuição de informações de produtos e serviços até a realização de transações entre as partes que compõem o ambiente de negócio. Assim, o CE passa pelos estágios de evolução da utilização do ambiente digital, devendo essa evolução ser entendida e garantida por meio dos aspectos a serem considerados na utilização do CE, visando a garantir o aproveitamento de suas contribuições, apresentando sinais dos impactos da evolução. Outra dimensão que completa a análise dos estágios do CE é a sua aplicação nos processos de negócio.

\section{Estrutura de análise de comércio eletrônico}

Albertin (2000a) definiu que a análise do CE deve ter como base principal duas dimensões - os aspectos a serem considerados na utilização do $\mathrm{CE}$ e as contribuições que a utilização do $\mathrm{CE}$ oferece às organizações - e elaborou a Estrutura de Análise de Comércio Eletrônico.

Os aspectos podem ser entendidos como sendo as áreas que devem ser analisadas e tratadas pelas em- 
presas para que possam implementar o CE e ter sucesso nessa estratégia de negócios, aproveitando as contribuições oferecidas.

As contribuições podem ser entendidas como as ofertas de oportunidades de negócios oferecidas pelo $\mathrm{CE}$, que as empresas poderão aproveitar caso tenham tratado adequadamente os aspectos.

\section{Comércio eletrônico e os processos de negócio}

Albertin (2000b) propôs a seguinte classificação de processos para a análise da assimilação do CE pelas organizações:

a) desenvolvimento de produto;

b) cadeia de suprimentos;

c) produção;

d) atendimento a clientes.

Cabe ressaltar que essa classificação é genérica para atender aos vários setores e que existe uma sobreposição de processos.

\section{PESQUISA}

A metodologia utilizada no projeto de pesquisa e na "Pesquisa FGV de Comércio Eletrônico no Mercado Brasileiro" foi a de pesquisa de campo por meio de questionário elaborado com base em várias pesquisas exploratórias anteriores, o que permitiu estudar os vários componentes desse novo ambiente.

A estratégia de pesquisa de campo está de acordo com as perguntas dessa pesquisa, que são:

a) Como as empresas estão utilizando as aplicações de CE?

b) O que as empresas estão realizando no novo ambiente digital?

c) Onde (na estrutura organizacional, nos processos de negócio, etc.) as empresas estão efetuando os esforços de CE?

d) Quanto dos processos de negócio estão sendo realizados utilizando as aplicações de CE?

e) Como as empresas estão avaliando os aspectos e as contribuições de CE?

O questionário abordou as seguintes categorias de informações:

a) Situação da empresa: para a avaliação da situação das empresas que participaram da pesquisa, foram considerados o porte em relação à sua receita líquida, os gastos e investimentos em TI e CE, bem como o nível de estruturação organizacional para essa utilização.

b) Situação do comércio eletrônico: buscou-se identificar a situação da aplicação do CE no relacionamento que as empresas mantêm com seus fornecedores e clientes, incluindo os consumidores finais.

c) Infra-estrutura de comércio eletrônico: a infra- estrutura de CE é formada pelas aplicações de TI que utilizam, de uma forma geral, a Internet como infra-estrutura de informação e comunicação pública.

d) Comércio eletrônico nos processos de negócio da empresa: foi analisada a utilização do CE por meio de sua aplicação nos processos de negócio, considerando quatro categorias de processos bastante amplas, desenvolvimento de produto/serviço, cadeia de suprimentos, manufatura e atendimento a clientes.

e) Aspectos do comércio eletrônico: estabeleceramse os aspectos considerados mais relevantes para a aplicação bem-sucedida do CE.

f) Contribuições do comércio eletrônico: foi verificado o grau de importância que as empresas atribuem ao $\mathrm{CE}$ em relação às contribuições oferecidas.

\section{Amostra}

A amostra utilizada na "Pesquisa FGV de Comércio Eletrônico no Mercado Brasileiro", realizada entre julho de 1999 e março de 2000, foi formada por aproximadamente 150 empresas, dos vários setores serviços, indústria e comércio -, conforme apresenta a Figura 1. As empresas participantes são organizações que atuam no ambiente tradicional e também estão atuando no ambiente de $\mathrm{CE}$, em maior ou menor nível, e aquelas que foram constituídas somente para esse ambiente.

A amostra de empresas que participaram da pesquisa apresentou uma adequada distribuição por faturamento, sendo maior a participação das empresas consideradas grandes e médias, conforme apresenta a Figura 2.

Figura 1 - Distribuição da amostra por setor

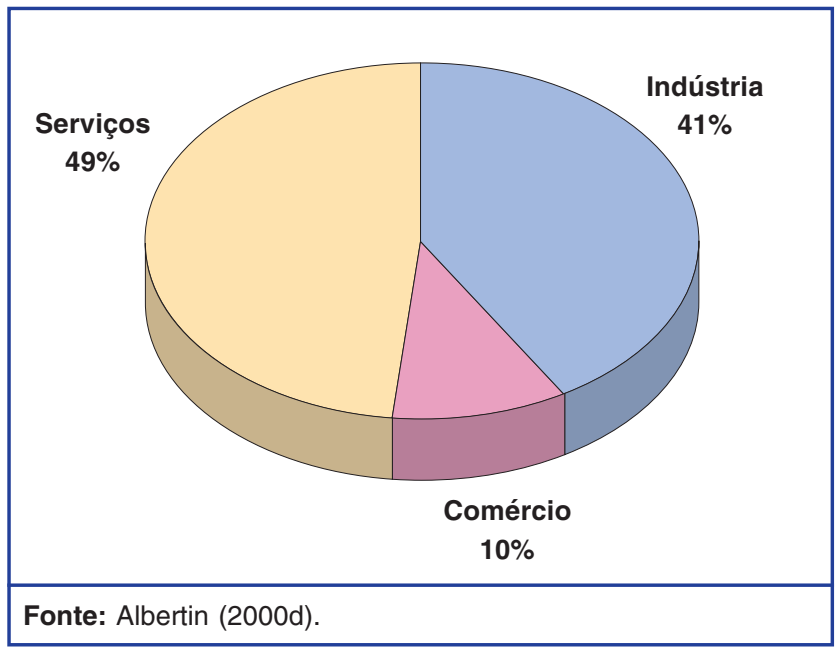


Figura 2 - Distribuição da amostra por faturamento

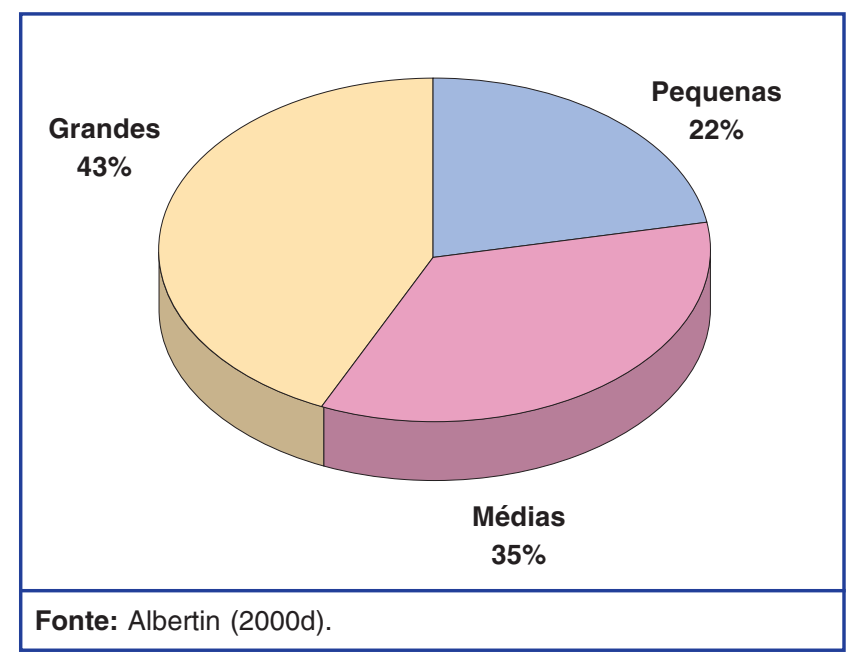

Figura 3 - Nível de CE no mercado brasileiro

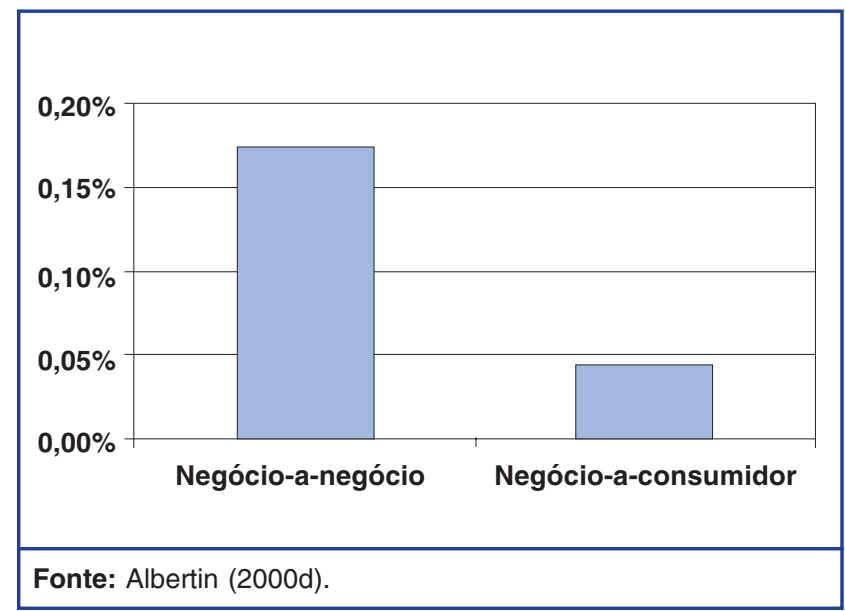

Figura 4 - Gastos e investimentos em TI e CE

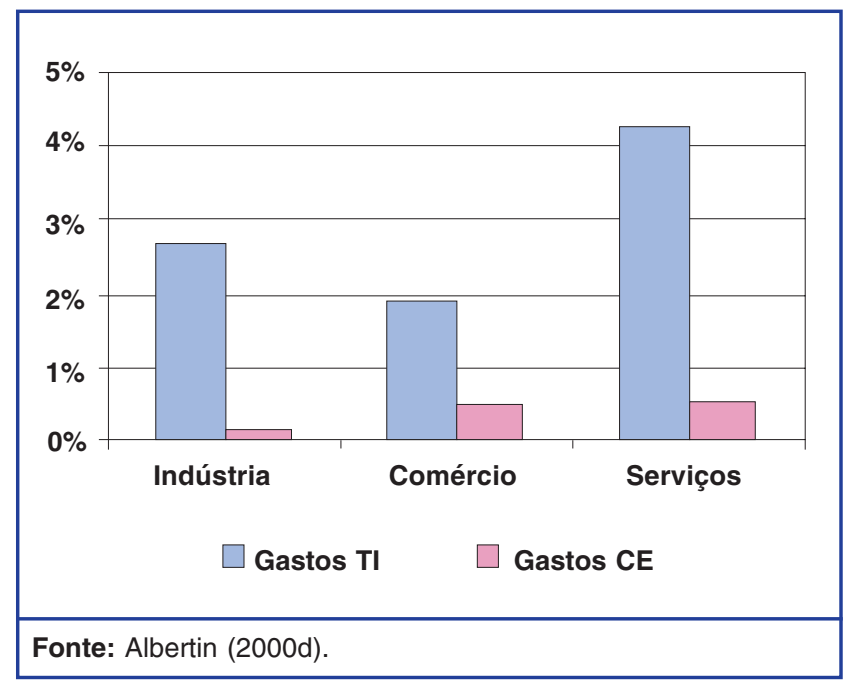

\section{COMÉRCIO ELETRÔNICO NO MERCADO BRASILEIRO}

A "Pesquisa FGV de Comércio Eletrônico no Mercado Brasileiro" comprova a evolução do CE nesse mercado, com um aumento de utilização das aplicações de CE pelas empresas e também com um crescimento do número de empresas que passaram a utilizar os meios eletrônicos nos seus processos de negócio. Embora os índices de valores praticados nesse ambiente em relação ao mercado como um todo sejam ainda baixos, apresentam crescimento significativo. A Figura 3 apresenta o nível de CE no mercado brasileiro, podendo ser entendido como o volume do mercado total, em valor, que já está sendo realizado no ambiente de CE tanto para as transações negócio-a-negócio quanto para as transações negócio-a-consumidor.

As empresas estão dedicando significativo esforço organizacional, incluindo investimentos e gastos, conforme apresenta a Figura 4, que compara os investimentos e gastos com $\mathrm{CE}$ com aqueles dirigidos para a TI como um todo.

Esses investimentos e gastos em CE já se refletem na estrutura organizacional das empresas com a criação de novas áreas e a conseqüente necessidade de profissionais com novos conhecimentos e habilidades. A Figura 5 apresenta a proporção das empresas que já têm áreas de CE.

As empresas estão utilizando cada vez mais a infraestrutura da Internet e das aplicações de CE como os meios para a realização de seus processos de negócio, com clara predominância daqueles relativos ao atendimento a clientes, conforme apresenta a Figura 6, que compara a situação das empresas em 1999 e 2000.

Essa utilização ainda está significativamente voltada para a disponibilização de informações institucionais e de produtos e serviços, mas com clara tendência à realização de transações.

O setor de indústria é o que apresenta maior índice de utilização de CE no seu relacionamento com fornecedores, cabendo lembrar que essa situação engloba a utilização da troca eletrônica de dados (EDI) tradicional, conforme apresenta a Figura 7.

O setor de comércio é o que apresenta maior índice de utilização de CE no seu relacionamento com clientes, conforme apresenta a Figura 8, sendo essa situação bastante influenciada pela utilização de homepages e catálogos eletrônicos para a divulgação de informações para os clientes.

Os processos referentes a atendimento a clientes são os que apresentam maiores índices de utilização das aplicações de CE, justificando uma análise mais detalhada dos seus subprocessos. 
Figura 5 - Empresas com áreas de CE

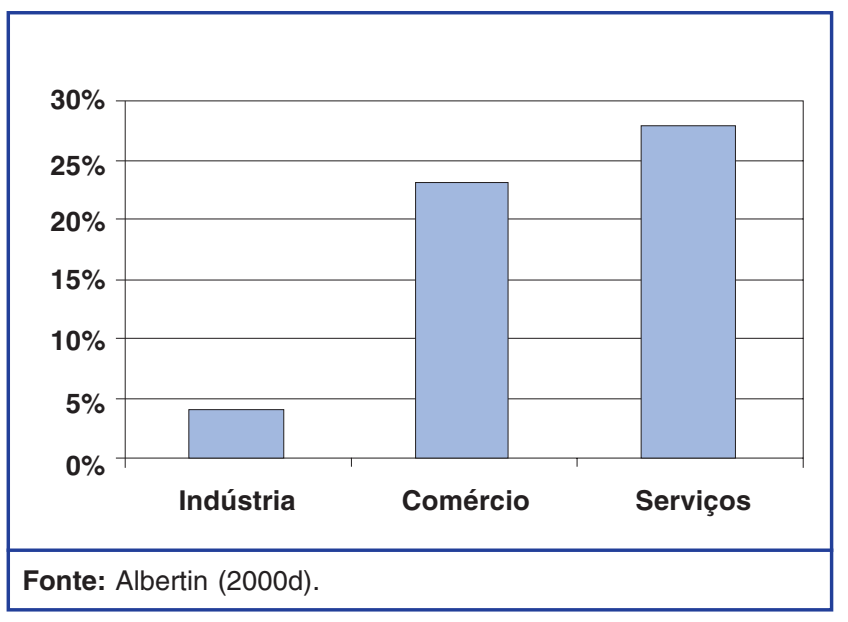

Um número bastante elevado de empresas utiliza as aplicações de CE nos seus subprocessos de divulgação de informação sobre produtos/serviços, conforme mostra a Figura 9, que apresenta a situação atual e a previsão de utilização pelas empresas.

Em relação aos demais subprocessos, o número de empresas que os utiliza é significativamente menor e essa situação tem previsão de algumas mudanças por parte das empresas.

A utilização das aplicações de CE apresenta bastante aderência em relação aos processos de negócio nos quais são utilizadas, concentrando-se nas aplicações já consideradas consolidadas, conforme apresenta a Figura 10, que compara a situação das empresas em 1999 e 2000.

Figura 6 - Evolução do CE e os processos de negócio

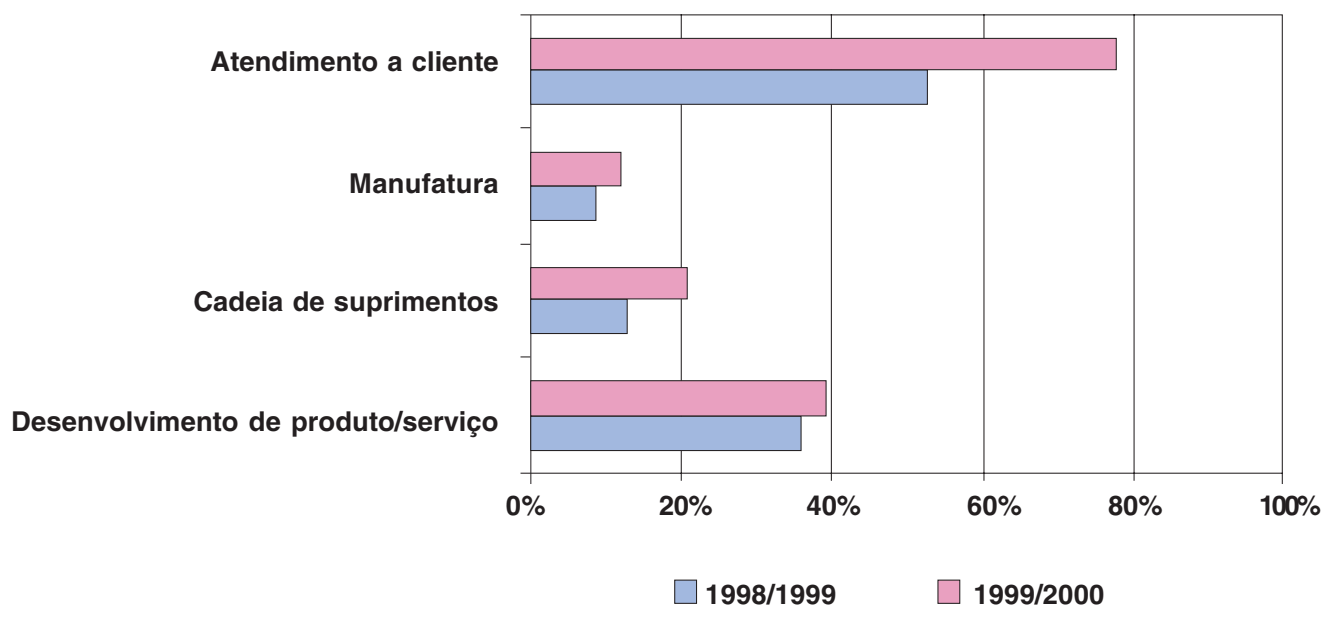

Fonte: Albertin (2000d).

Figura 7 - CE no relacionamento com fornecedores

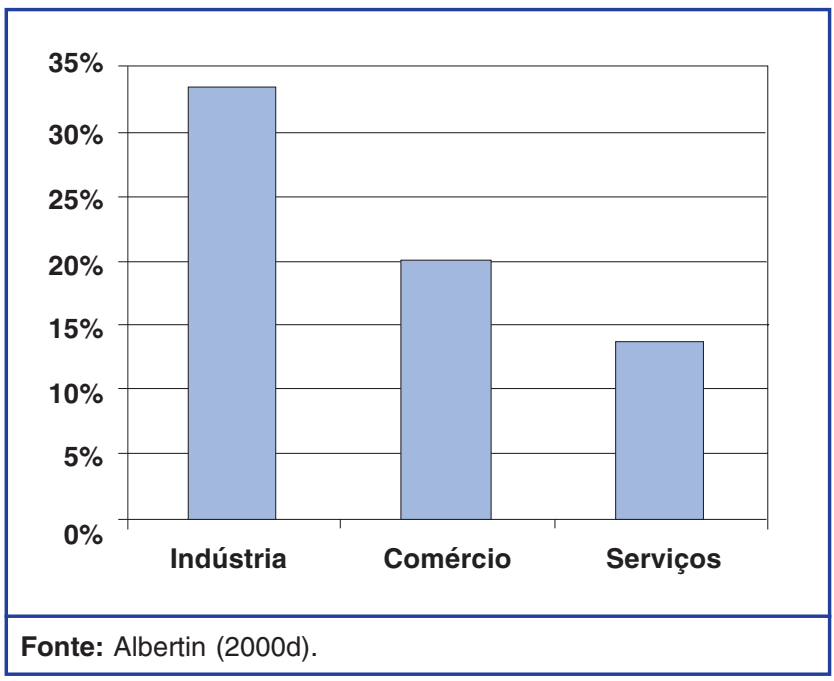

Figura 8 - CE no relacionamento com clientes

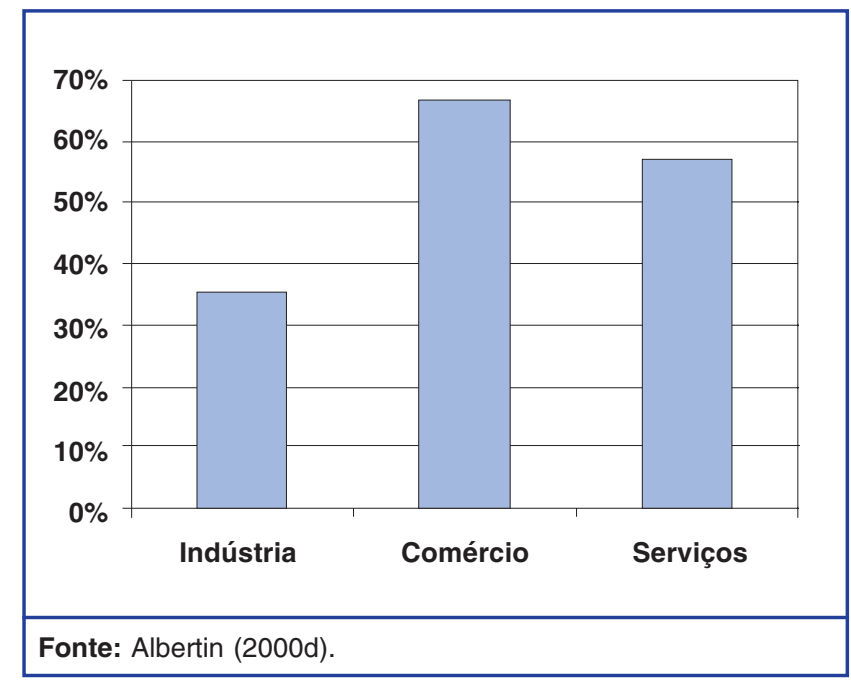


As aplicações utilizadas permitem que as empresas assimilem esse novo ambiente digital sem grandes revoluções imediatas, tanto para a adoção por parte de seus participantes quanto de seus fornecedores e clientes.
As aplicações com maior utilização são aquelas necessárias para a realização dos subprocessos que as empresas estão mais fortemente direcionando para o ambiente digital.

A maior mudança prevista é em relação à utiliza-

Figura 9 - CE nos processos de atendimento a clientes por subprocessos

Suporte à utilização de produtos e serviços

Distribuição de produtos e serviços

Aceitação de pagamentos

Processamento de pedidos

Recebimento de pedidos

Obtenção de informações sobre necessidades/preferências

Negociação de preço e condições

Facilidade para seleção de produtos/serviços

Divulgação de informação sobre produtos/serviços

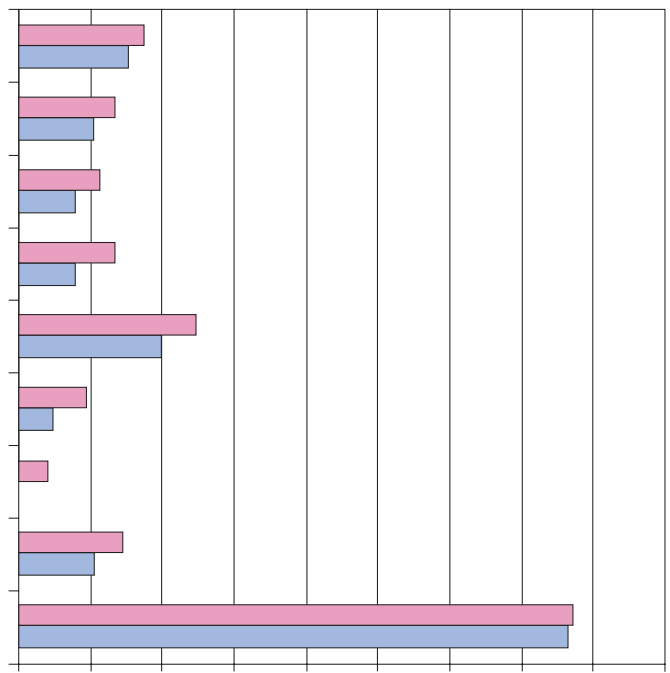

$\begin{array}{llllllllllll}0 & 0 & 10 \% & 20 \% & 30 \% & 40 \% & 50 \% & 60 \% & 70 \% & 80 \% & 90 \%\end{array}$

$\square$ Atual $\quad \square$ Futuro

Fonte: Albertin (2000d).

Figura 10 - Evolução da utilização das aplicações de CE

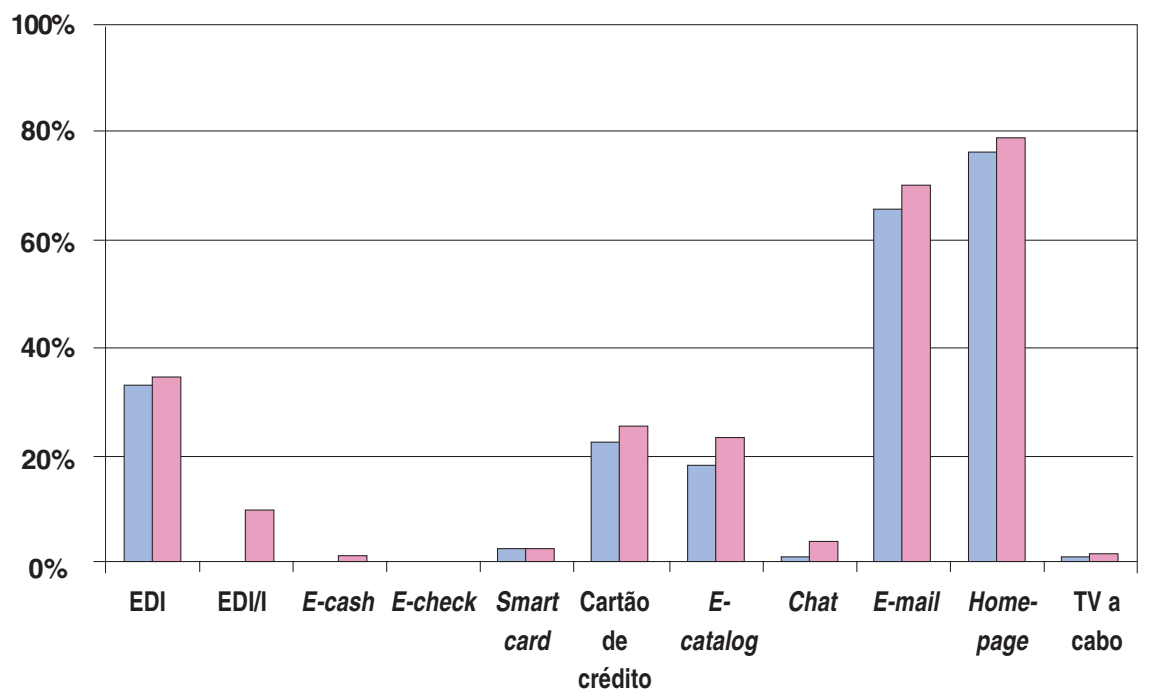

$1998 / 1999$

$1999 / 2000$

Fonte: Albertin (2000d). 
ção da troca eletrônica de dados pela Internet (EDI/ I), confirmando que as empresas percebem a Internet como uma infra-estrutura pública que permite realizar integração eletrônica com restrições mínimas.

\section{A evolução do comércio eletrônico no mercado brasileiro}

O comércio eletrônico no mercado brasileiro está consolidado e apresenta claros sinais de evolução, mesmo que ainda possa ser considerado em um estágio intermediário de expansão.

A análise dos resultados da pesquisa permite avaliar o estágio em que se encontra o CE no Brasil, identificando a sua evolução, o cenário atual e as suas tendências.

A grande ênfase da utilização das aplicações de CE nos processos de negócio relativos ao relacionamento com clientes, mais especificamente àqueles voltados para a disponibilização de informações sobre produtos e serviços, desde o passado recente, demonstra que as empresas já utilizam esse ambiente num primeiro estágio de evolução já consolidado.

A busca da expansão da realização de transações, comprovada principalmente pelos processos de recebimento de pedidos, permite identificar o início da utilização de transações para o oferecimento de interação e disponibilização de transações, possibilitando o surgimento das comunidades de transações.

A realização de subprocessos de distribuição de produtos e serviços, ainda que não intensa, é a inser- ção das empresas nesse ambiente para a realização desse processo.

A realização dos subprocessos de obtenção de informações sobre necessidades e preferências permite identificar a evolução para a utilização intensa do ambiente digital com a efetivação da organização de tempo real, também podendo ser entendido como parte do ambiente das comunidades de interesse e do relacionamento um-a-um. Esse cenário consolida-se com a previsão futura de realização dos subprocessos de negócio sobre preços e condições.

A evolução do CE no mercado brasileiro compreende quatro grandes estágios para a formação do novo ambiente de negócios como um todo, sendo formada por a) informação, b) distribuição, c) transação e d) comunicação, conforme definido por Albertin (2000c). A Figura 11 apresenta essa evolução.

A análise dessa evolução, com as realizações já empreendidas, possibilita a identificação da busca pelo novo ambiente de negócio, formado por comunidades de pessoas e empresas. A indicação "atual" deve ser entendida como sendo o estágio atual da busca de realização de transação e distribuição de produtos e serviços nesse novo ambiente, e não uma indicação de uma situação já consolidada.

\section{CONCLUSÕES}

A "Pesquisa FGV de Comércio Eletrônico no Mercado Brasileiro" (Albertin, 2000d) fornece importantes subsídios para entender o cenário atual e elaborar

Figura 11 - Evolução do comércio eletrônico no mercado brasileiro

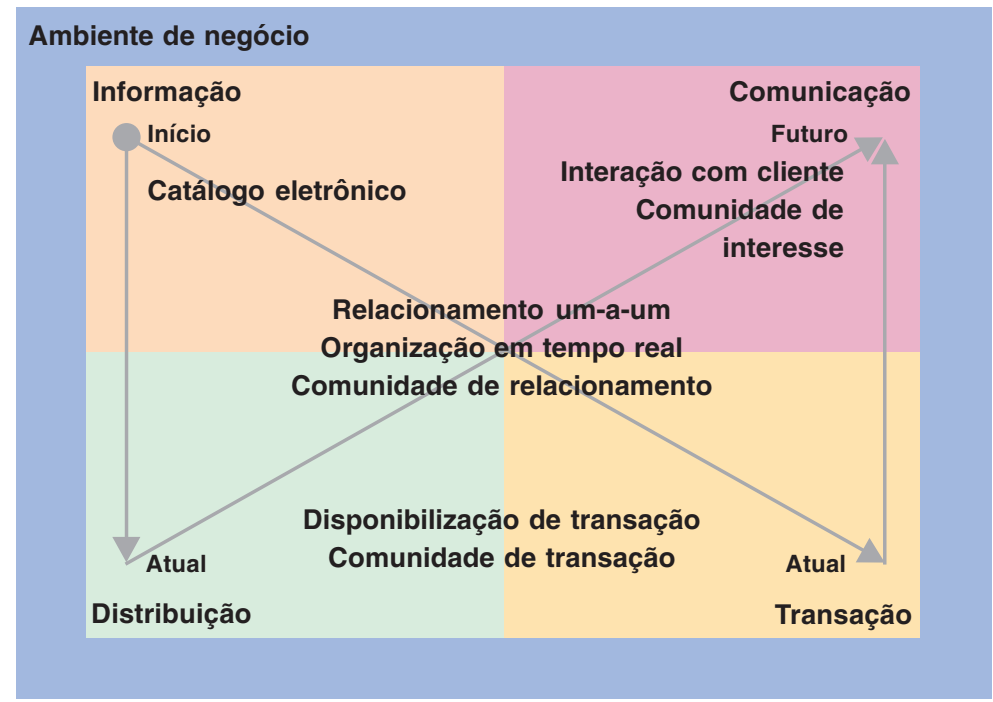


suas tendências, possibilitando avaliar os estágios de evolução e seus desafios. Os estudos atuais para a nova edição da pesquisa ainda indicam poucas mudanças significativas no cenário atual.

As aplicações de CE mais intensamente utilizadas pelas empresas pesquisadas ainda são basicamente aquelas que já podem ser consideradas como bastante assimiladas nesse novo ambiente, incluindo homepage, correio eletrônico e troca eletrônica de dados.

A utilização das aplicações de CE para a integração das empresas com seus clientes já é praticada por aproximadamente $60 \%$ das empresas pesquisadas, destacando-se aquelas dos setores de comércio e serviços.

Atualmente, as empresas estão utilizando as aplicações de CE principalmente nos processos referentes à divulgação de informações sobre produtos e serviços. As empresas prevêem que os próximos processos a serem apoiados nessas novas tecnologias serão os referentes a transações e troca de informações.

O desempenho da infra-estrutura pública de comunicação, Internet, utilizada pelas aplicações de CE ainda não restringe a sua utilização pelas empresas. Essa situação, no entanto, pode vir a restringir a expansão dos processos que envolvam transações e conteúdo. As mudanças tecnológicas atuais demonstram que o ambiente está sendo preparado para evitar tal situação.

Os aspectos avaliados como relevantes na pesquisa revelam amplamente o amadurecimento do mercado brasileiro em relação ao $\mathrm{CE}$, ao considerar os aspectos necessários para mais um ciclo de expansão da utilização dos meios eletrônicos nos processos de negócio, conforme apresenta a Figura 12, que compara a situação das empresas em 1999 e 2000.

As empresas avaliam como mais importantes os aspectos de segurança e legais, o que é considerado coerente com a utilização atual e as tendências, ou seja, a busca pela utilização de CE nos processos que envolvem troca de informação e transações exige um ambiente com segurança mais efetiva, ao mesmo tempo em que as características desse novo ambiente exigem revisão e adequação dos aspectos legais atuais para sua expansão.

A mudança mais importante está relacionada com a distinção que as empresas estão fazendo entre os vários aspectos, deixando de considerar importante tudo ao mesmo tempo e privilegiando aqueles aspectos relativos à segurança e à privacidade, condição necessária para a evolução do CE.

Os próximos aspectos que devem receber maior atenção das empresas é a adequação organizacional e tecnológica, o relacionamento com fornecedores e os sistemas eletrônicos de pagamento, para viabilizar a utilização das aplicações de CE para a realização de transações.

A avaliação das contribuições oferecidas pelo $\mathrm{CE}$ também demonstra o amadurecimento do mercado

Figura 12 - Evolução da avaliação dos aspectos de CE

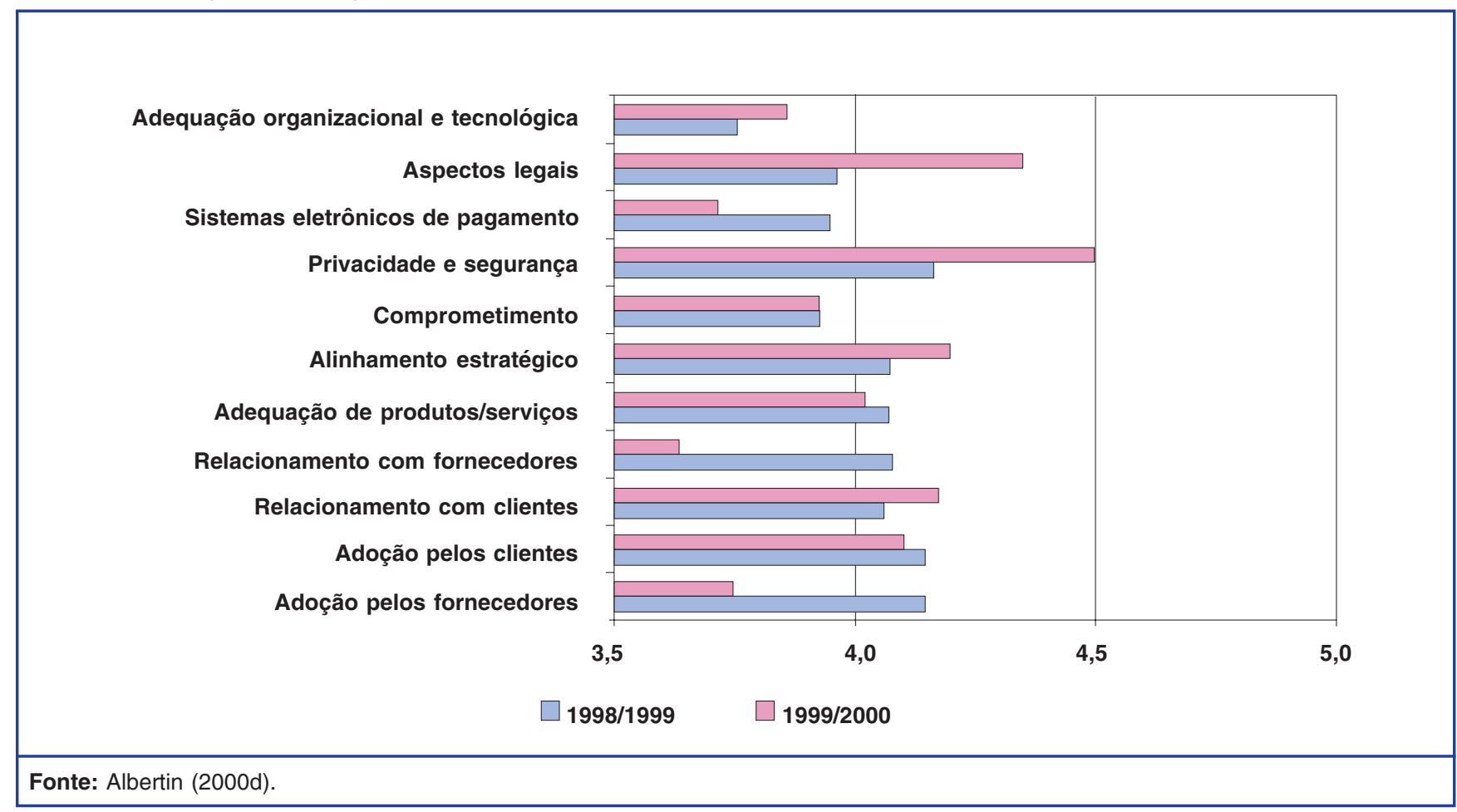


Figura 13 - Evolução da avaliação das contribuições de CE

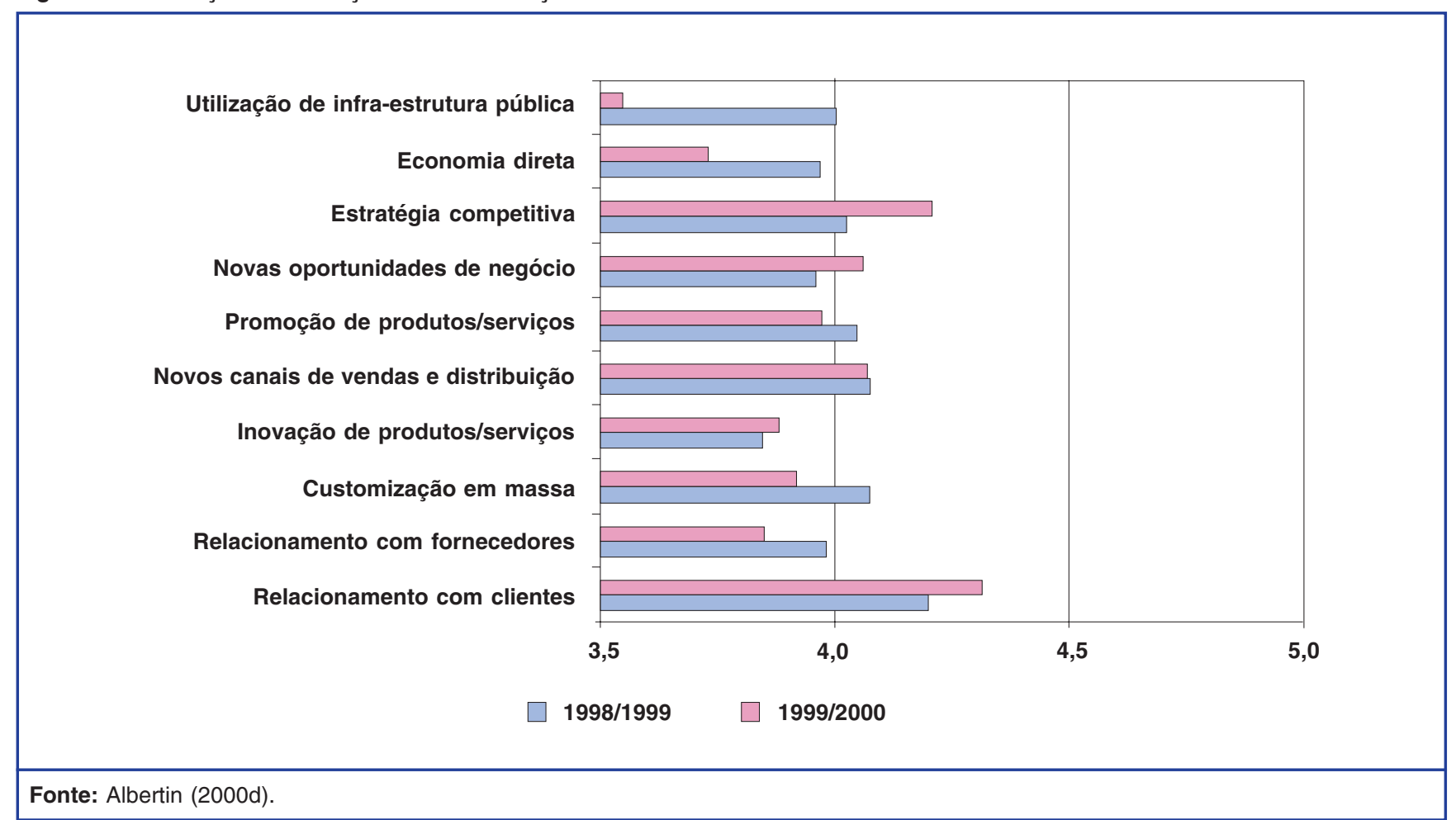

brasileiro e a coerência com a importância atribuída aos vários aspectos, conforme apresenta a Figura 13, que compara a situação das empresas em 1999 e 2000 .

A consolidação da melhoria do relacionamento com clientes confirma o CE como sendo o grande facilitador da integração eletrônica da empresa com seus clientes, que permitirá a realização de processos voltados para a identificação e satisfação das necessidades destes.

Essa situação garante melhores armas competitivas para as empresas, a exploração de novas oportunida- des e a utilização de novos canais de vendas e distribuição.

Os resultados da "Pesquisa FGV de Comércio Eletrônico no Mercado Brasileiro" possibilitam concluir que as empresas já estão efetivamente utilizando o $\mathrm{CE}$, porém ainda focando principalmente uma parte dos seus processos de negócio, que são aqueles referentes ao relacionamento externo com seus clientes. O próximo estágio da sua evolução será permear também os processos internos e integrá-los com os externos de forma automática, criando o novo ambiente de negócio.

REFERÊNCIAS BIBLIOGRÁFICAS

ALBERTIN, A. L. Administração de informática: funções e fatores críticos de sucesso. 2. ed. São Paulo: Atlas, 1999

ALBERTIN, A. L. Comércio eletrônico: modelo, aspectos e contribuições de sua aplicação. 2. ed. São Paulo : Atlas, 2000a.
ALBERTIN, A. L. Comércio eletrônico: situação atual tendências. São Paulo : EAESP/FGV, 2000b. Projeto de pesquisa desenvolvido com o apoio do Núcleo de Pesquisas e Publicações (NPP) da Escola de Administração de Empresas de São Paulo (EAESP) da Fundação Getulio Vargas (FGV).

ALBERTIN, A. L. Evolução do comércio eletrônico no mercado brasileiro. In: ENCONTRO NACIONAL DA ASSOCIACẼ̃O DE
PÓS-GRADUAÇÃO EM ADMINISTRAÇÃO 2000, Florianópolis Anais... Florianópolis : ENANPAD, 2000c.

ALBERTIN, A. L. Pesquisa FGV de comércio eletrônico no mercado brasileiro. São Paulo : EAESP/FGV, 2000d. Programa de Excelência em Negócios na Era Digital do Centro de Informática Aplicada da Escola de Administração de Empresas de São Paulo (EAESP) da Fundação Getulio Vargas (FGV). Disponível na Internet: <www.fgvsp.br/cia/ce>. 